\title{
Fentanyl Uptake by the Scimed Membrane Oxygenator
}

\author{
David Rosen, MD, Kathleen Rosen, MD, Bruce Davidson, and Lynn Broadman, MD
}

With the initiation of cardiopulmonary bypass (CPB), using a membrane oxygenator, the drop in circulating fentanyl concentration is greater than can be attributed to dilution alone. This study examined the Scimed brand (2A-800) membrane oxygenator as a site of fentanyl binding. Initial experiments used an assembled CPB circuit. Subsequent dissection and analysis of the oxygenator revealed that the siliconebased membrane sheets were the primary site of fentanyl binding. The silicone-containing waterproof wrapper was also responsible for $1 \%$ to $2 \%$ of fentanyl binding. Binding of fentanyl to the Scimed membrane oxygenator occurs at a rapid rate and continues until the membrane has taken up 130 $\mathrm{ng} / \mathrm{cm}^{2}$ of membrane surface area. The interaction is complete by 15 to 30 minutes if suprasaturated concentrations are used. Samples of membrane material with a surface area of $1 \mathrm{~cm}^{2}$ were also studied. Isolated membrane squares in a nonmoving prime solution required two hours for saturation at the same fentanyl concentrations as the intact membrane with circulating prime. Introduction of motion

I N RECENT YEARS, the usc of high-dose narcotic anesthesia for cardiac surgery has become very popular. Fentanyl is a commonly selected agent because of its minimal cardiovascular side effects. The pharmacokinetics of fentanyl have been studied in both adults and children and are well understood in the nonbypass setting. ${ }^{1-3}$ Use of the cardiopulmonary bypass (CPB) circuit is assumed to alter fentanyl kinetics if only by dilution and expansion of the circulating blood volume. Many studies describe this phenomenon..$^{3-7}$ Koren et al were the first to note that the decrease in fentanyl plasma levels upon initiation of CPB was much greater than was predicted from the increased volume of distribution alone. ${ }^{3,5,7}$ They demonstrated that therapeutic fentanyl concentrations $(>20 \mathrm{ng} /$ $\mathrm{mL}$ ) rapidly fell to low subtherapeutic levels upon initiation of bypass using a silicone-based membrane oxygenator. This group postulated that the site of fentanyl absorption was the membrane oxygenator. ${ }^{3,5,7}$ They also showed no significant fentanyl absorption by the PVC tubing in their circuit. Skacel et al showed that absorption in the bypass circuit also occurs when a bubble oxygenator is used. ${ }^{8}$ Unfortunately, because many early clinical studies have failed to identify the oxygenator brand and type, comparisons are difficult. Maintenance of anesthesia and to the priming solution accelerated the rate of fentanyl binding by the isolated membrane squares to a rate similar to the intact membrane. Motion also provided results similar to those previously reported using different analysis techniques. Therefore. this method of studying fentanyl-membrane interactions using samples of membrane and tritiated fentanyl is a valid model for the intact membrane oxygenator in the assembled bypass circuit. In addition to solution movement, fentanyl concentration of the priming solution was also found to affect the rate of fentanyl uptake. When fentanyl concentrations were used which were insufficient to achieve saturation of the membrane $(10 \mathrm{ng} / \mathrm{mL}$ and $20 \mathrm{ng} / \mathrm{mL}$ ), the rate of uptake was slowed. Binding of all available fentanyl under these conditions occurred within three hours. There is potential modification of this interaction by several clinically relevant factors, including temperature, pH, protein content of prime solution, and other drugs. These areas require further study before the saturation data are applied to clinical practice. - 1988 by Grune \& Stratton, Inc.

therapeutic fentanyl levels throughout the surgical procedure, including the bypass period, is optimal for the patient undergoing cardiac surgery. Plasma fentanyl levels $>20 \mathrm{ng} / \mathrm{mL}$ are required to prevent the stress response to surgery. Previous clinical studies have not been able to achieve this goal. It is necessary to have a better understanding of fentanyl pharmacokinetics in the CPB system before approaching this clinical dilemma. The purpose of this study was twofold. The first was to study the interaction of an intact CPB circuit using a membrane oxygenator and fentanyl, including the possible determination of a saturation point. The second goal was to develop and verify an experimental method, which is performed in a small, material-conserving model and is an accurate representation of the entire membrane within the CPB circuit.

From C. S. Mott Children's Hospital, University of Michigan, Ann Arbor; and Children's Hospital, National Medical Center, Washington, DC.

Supported in part by Janssen Pharmaceuticals.

Presented in part at the annual meeting of the American Society of Anesthesiologists, San Francisco, CA.

Address reprint requests to David A. Rosen. MD. C. S. Mott Children's Hospital, The University of Michigan, Rm C4128, Box 0800, Ann Arbor, MI 48109-0800. (c) 1988 by Grune \& Stratton, Inc. 0888-6296/88/0205-0006\$03.00/0 


\section{METHODS}

\section{Intact Cardiopulmonary Bypass Studies}

A CPB circuit was assembled using $1 / 4$ in PVC tubing, a bubble trap, and a $2 \mathrm{~A}-800$ Scimed membrane.

Experiment 1. The CPB system was primed with 50 $\mu \mathrm{g}$ tritiated fentanyl in $400 \mathrm{~mL}$ of Normosol $\mathrm{R}$ balanced to $\mathrm{pH} 7.4$ to produce a fentanyl concentration of $125 \mathrm{ng} / \mathrm{mL}$. Flow in the CPB circuit was maintained at $1.0 \mathrm{~L} / \mathrm{min}$, and temperature was a constant $23^{\circ} \mathrm{C}$. At time zero, a $0.5 \mathrm{~mL}$ sample was obtained as the liquid made its first pass through the membrane. Then, every 15 minutes for two hours an additional $0.5 \mathrm{~mL}$ aliquot was obtaincd for fentanyl analysis. At each time interval, the fentanyl analysis was performed twice. At the completion of the run, the oxygenator was dissected and random selection of membrane squares at four locations and a $1 \mathrm{~cm}^{2}$ sample of the silicone wrapper were obtained (Fig 1). The components were analyzed for fentanyl by radionuclear technique.

Experiment 2. The CPB system was primed with $300 \mathrm{~mL}$ of Normosol R. After debubbling, 1,100 $\mu \mathrm{g}$ of fentanyl was added to produce a measured fentanyl concentration of $367 \mathrm{ng} / \mathrm{mL}$. The prime was then circulated at a flow of $1.0 \mathrm{~L} / \mathrm{min}$ at $23^{\circ} \mathrm{C}$. Aliquots of $0.5 \mathrm{~mL}$ of the circulating prime solution were obtained for fentanyl analysis at 30 seconds, 5 minutes, 15 minutes, and then every 15 minutes for the next 2.75 hours. Analysis was performed in duplicate. As in experiment 1, the oxygenator was then dissected, and two samples of the silicone outer sheet and six samples of the membrane itself were removed for fentanyl analysis.

\section{Isolated Membrane Studies}

Samples of membrane material from the oxygenator were used. Pieces of membrane $1 \times 1 \mathrm{~cm}$ were obtained. The surface area of each membrane square was calculated using the dry weight and the known density $\left(0.01399 \mathrm{~g} / \mathrm{cm}^{2}\right)$ supplied by the manufacturer.

Experiment 3. Eighteen $1 \times 1 \mathrm{~cm}$ squares of membrane oxygenator material were placed in the same vessel containing $5 \mathrm{~mL}$ of fentanyl in Normosol R solution at $23^{\circ} \mathrm{C}$. The fentanyl concentration was $125 \mathrm{ng} / \mathrm{mL}$. A pair of membrane samples was removed immediately at time zero. The remaining membrane squares were incubated in the fentanyl solution and two membrane squares were subsequently removed at 15 minute intervals for two hours.

Experiment 4. A $1 \mathrm{~cm}$ piece of the membrane was placed in each of 32 test tubes. Two additional test tubes containing no membrane were run concurrently as a control. One milliliter of a solution containing $340 \mathrm{ng} / \mathrm{mL}$ of fentanyl in Normosol $R$ was added to each tube. This fentanyl concentration was estimated to be greater than the saturation capacity of the membrane. Immediately after immersion, the membranes were removed in the time zero test tubes. Paired membrane samples were removed every 15 minutes for 225

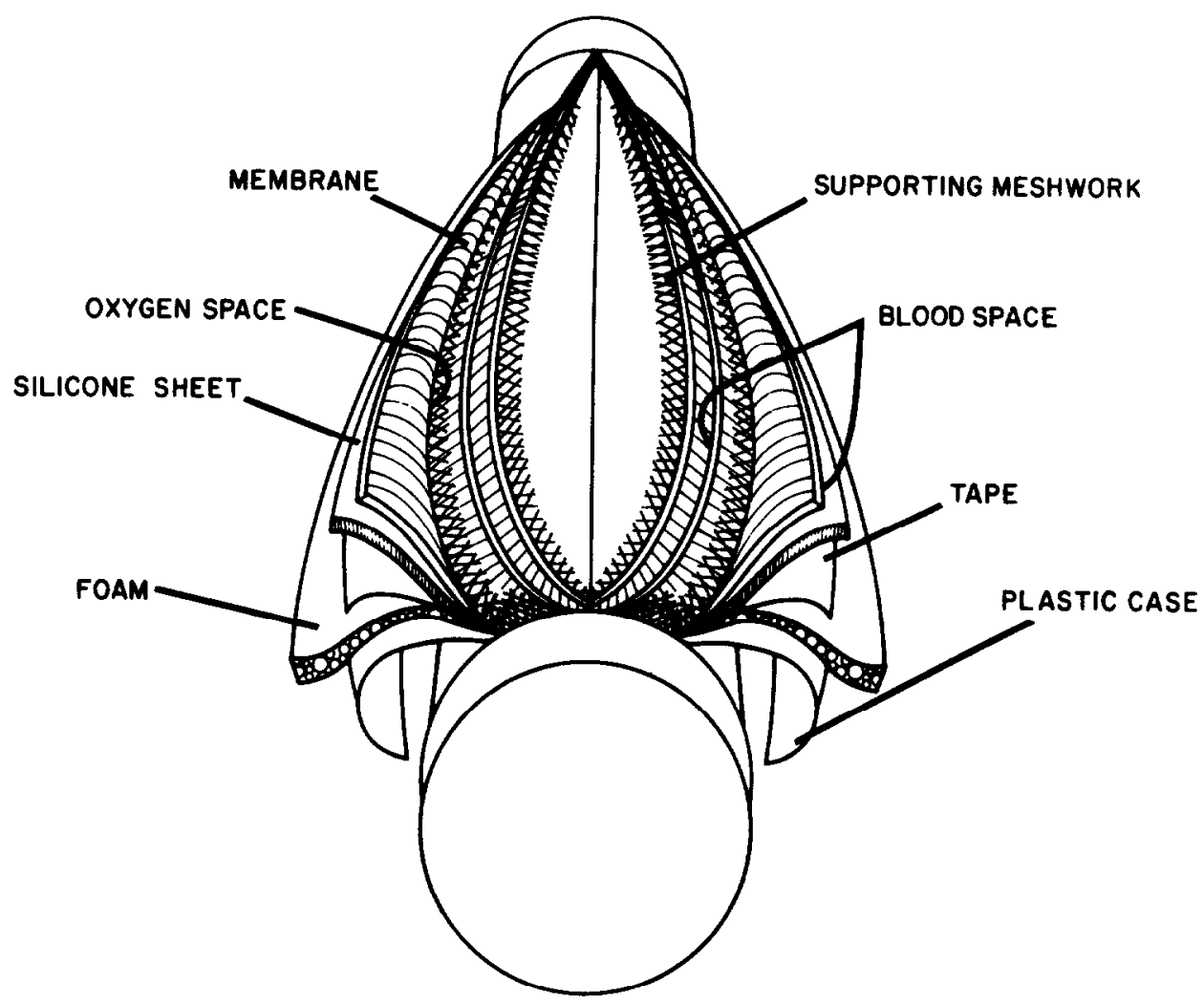

Fig 1. Detailed view of Scimed oxygenator. 
minutes. This experiment was repeated using decreasing fentanyl concentrations. The additional solutions studied contained fentanyl $255,200,20$, or $10 \mathrm{ng} / \mathrm{mL}$.

Experiment 5. A $1 \mathrm{~cm}^{2}$ membrane sample was placed in a tube containing $2 \mathrm{~mL}$ of $114 \mathrm{ng} / \mathrm{mL}$ of fentanyl in Normosol R solution. The solution was continuously mixed in a Vortex Genie mixer (Scientific Products, American Hospital Supply, McGaw Park, IL). Ten microliter samples of the circulating fluid were obtained at $0,0.5,5,10,15,30,45,75$ minutes and analyzed for fentanyl content. This entire experiment was repeated in identical fashion to produce a second set of data points at the same time intervals.

\section{Fentanyl Analysis}

Each of the experiments used tritiated fentanyl to demonstrate the interaction of fentanyl with the membrane oxygenator of the CPB circuit. Analysis of fentanyl binding was quantitated using liquid scintillation counting. The tritiated fentanyl base was donated by Janssen Pharmaceuticals (IRE Institut National des Radioelements National Institut Voor Radio-Elementen B-6220, Fleurus, Belgium). The concentration of fentanyl was $50 \mu \mathrm{g} / \mathrm{mL}$. The specific activity was $15 \mathrm{Ci} / \mathrm{mmol}$, yielding a radioactive concentration of 1 $\mathrm{mCi} / \mathrm{mL}$.

Samples were placed in $2.5 \mathrm{~mL}$ aquasol solution and then into a Beckman LS 7500 scintillation counter (Beckman Instruments, Fullerton, CA). The counts per minute from the counter samples were converted to disintegrations per minute (dpm) using the $\mathrm{H} \#$ quench correction method.* The dpm was then mathematically manipulated as listed below to yield the concentration of fentanyl in the sample.

$\frac{\mathrm{dpm}}{\text { volume of sample }} \times$ Total volume $\times 336,460 \mu \mathrm{g} / \mathrm{mmol}$

$\left(2.22 \times 10^{12}\right) \mathrm{dpm} / \mathrm{Ci} \times 15 \mathrm{Ci} / \mathrm{mmol}$

$=\mu \mathrm{g}$ fentanyl.

\section{RESULTS}

Through use of a radiolabeling technique, the primary site of fentanyl uptake by the CPB apparatus was definitely identified as the membrane oxygenator. Not only the membrane material but also the silicone wrapper has affinity for fentanyl. When the membrane was dissected, $1 \%$ $(0.5 \mu \mathrm{g})$ of the prime fentanyl was found on the silicone wrapper. In experiment 1 , the intact membrane was responsible for a $68 \%$ decrease in the circulating fentanyl concentration after only one pass through the membrane (Table 1). After two hours, $>92 \%$ of the initial circulating fentanyl had become bound to the oxygenator. The

${ }^{*} \mathrm{H}-\mathrm{Number}$ and AQC, Beckman Instructions \#015555874 LS 7500 Liquid Scintillation System operating manual, pp 5-9.
Table 1. Fentanyl Levels From Intact Circulating Cardiopulmonary Bypass Circuit

\begin{tabular}{rccc}
\hline $\begin{array}{c}\text { Time } \\
\text { (min) }\end{array}$ & $\begin{array}{c}\text { Measured } \\
\text { Pump Prime } \\
\text { Fentariy/ Content } \\
\text { (ng/mL) }\end{array}$ & $\begin{array}{c}\text { Assumed Membrane } \\
\text { Fentanyl Uptake in } \\
\text { Oxygenator* }\end{array}$ \\
\hline-10 & 125 & 0 & $\begin{array}{c}\text { Calculated } \\
\text { Fentanyl } \\
\text { Bound (\%) }\end{array}$ \\
0 & 40 & 4.3 & 0 \\
15 & 30 & 4.8 & 68.5 \\
30 & 20 & 5.3 & 76.7 \\
45 & 18 & 5.4 & 84.7 \\
60 & 15 & 5.5 & 86.8 \\
75 & 12 & 5.6 & 88.7 \\
90 & 12 & 5.6 & 90.8 \\
105 & 10 & 5.8 & 90.8 \\
120 & 10 & 5.8 & 92.7 \\
\hline
\end{tabular}

*Assumed fentanyl uptake calculated by loss in fentanyl from the prime divided by the membrane surface area of the oxygenator.

fentanyl concentration had fallen from 125 to 10 $\mathrm{ng} / \mathrm{mL}$, with a resultant membrane uptake of 5.8 $\mathrm{ng} / \mathrm{cm}^{2}$.

The behavior of the intact membrane exposed to a higher concentration of fentanyl was studied in experiment 2. Rapid fentanyl uptake occurred during the first 15 to 30 minutes. The membrane appeared to become saturated at $\sim 130 \mathrm{ng} / \mathrm{cm}^{2}$ (Fig 2). Prior to saturation, uptake could be described by the formula: uptake (ng/ $\left.\mathrm{cm}^{2}\right)=0.96 \pm 23.4 x$, where $x=$ time in minutes. At the end of the circulation period, random samples from the dissected membrane were also analyzed. As in experiment 1, analysis of the silicone wrapper revealed fentanyl binding. The wrapper of the 2A-800 membrane with a surface area of $512 \mathrm{~cm}^{2}$ contained $44 \mathrm{ng} / \mathrm{cm}^{2}$ of fentanyl. With a suprasaturated fentanyl solution, the wrapper bound $1 / 3$ the amount of fentanyl $/ \mathrm{cm}^{2}$ as the membrane material. Owing to the much smaller surface area, $<2 \%$ of fentanyl in the oxygenator was bound to the wrapper. By extrapolation, all the fentanyl that disappeared from the circulating prime could be accounted for bound to the membrane or silicone wrapper.

The uptake of fentanyl by isolated oxygenator membrane squares is demonstrated in experiment 3 (Table 2). At time zero (the equivalent of one pass through the oxygenator), the uptake of fentanyl was $3 \mathrm{ng} / \mathrm{cm}^{2}$. The rate of decline in fentanyl concentration in the prime corresponding to membrane uptake was less rapid in experiment 3 than in experiment 1 . At the 120 minute sample interval, neither a plateau 


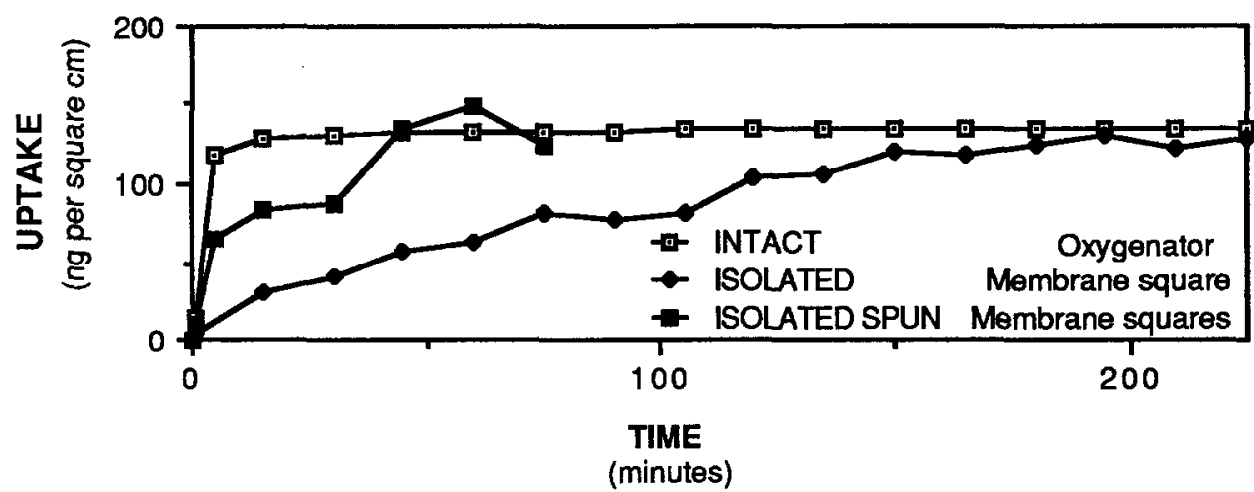

Fig 2. Uptake of intact and isolated membranes exposed to circulated and uncirculated priming solutions containing fentanyl in suprasaturated concentretions.

in fentanyl uptake nor complete uptake of all available fentanyl had occurred.

Experiment 4 demonstrates the conservation of tritiated fentanyl mass in the liquid and solid phases (Table 3). Throughout the experiment, the total number of nanograms of fentanyl recovered from both the liquid and the membrane surface as assessed by liquid scintillation counting was $340 \mathrm{ng} \pm 10 \%$. No change in the fentanyl concentration was observed in the control tubes over time. After 150 minutes, the membranes approached saturation with an uptake of $130 \mathrm{ng} / \mathrm{cm}^{2}$. Similar results were obtained with the subsequent suprasaturated priming solutions (Table 4) of 255 and 200 $\mathrm{ng} / \mathrm{mL}$. The correlation between the rate of binding and capacity of uptake by the various suprasaturated fentanyl priming solutions were similar at $r^{2}=0.982$. The uptake over time for priming solutions containing a fentanyl concen-

Table 2. Concentration of Fentanyl Bound to 18 Membrane Squares $(1 \mathrm{~cm})^{*}$ Placed in $625 \mathrm{ng}$ of Fentanyi in $5 \mathrm{~mL}$ of Normosol $\mathrm{A}$

\begin{tabular}{cc}
\hline Time $($ min) & $\begin{array}{c}\text { Fentanyl Bound } \\
\text { to Membrane } \\
\left(\mathbf{n g} / \mathrm{cm}^{2}\right)\end{array}$ \\
\hline-10 & 0 \\
0 & 3 \\
15 & 4 \\
30 & 12 \\
45 & 17 \\
60 & 21 \\
75 & 22 \\
90 & 24 \\
105 & 27 \\
120 & 30 \\
\hline
\end{tabular}

- Two membrane samples were removed at each time interval, and their fentanyl concentration was averaged. tration greater than that required for saturation is shown in Fig 3. Under these conditions, uptake can be predicted by the following best fit equation: Uptake $\left(\mathrm{ng} / \mathrm{cm}^{2}\right)=10.73+1.02$ $x-0.002 x^{2}$ where $x=$ time (minutes). Membrane squares exposed to clinically applicable concentrations of tritiated fentanyl, 10 and 20 $\mathrm{ng} / \mathrm{mL}$, were also studied in experiment 4 . Incubation of membrane squares in these solutions resulted in uptake of all available fentanyl. In the $10 \mathrm{ng} / \mathrm{mL}$ prime, $10 \mathrm{ng} / \mathrm{cm}^{2}$ was achieved and in the $20 \mathrm{ng} / \mathrm{mL}$ prime $20 \mathrm{ng} / \mathrm{cm}^{2}$ was achieved. The uptake over time for the 10 and $20 \mathrm{ng} / \mathrm{mL}$ subsaturated primes are shown in Fig 4. In both solutions, uptake of $>99 \%$ of the initially available fentanyl occurs by three hours. The proportion of fentanyl bound to the membrane compared to the amount in solution is similar for both

Table 3. Concentration of Fentanyl in Membrane and Liquid Exposed to $340 \mathrm{ng}$ of Fentanyl

\begin{tabular}{rccc}
\hline $\begin{array}{c}\text { Time } \\
\text { (min) }\end{array}$ & $\begin{array}{c}\text { Membrane } \\
\text { (ng) }\end{array}$ & $\begin{array}{c}\text { Liquid } \\
\text { (ng) }\end{array}$ & $\begin{array}{c}\text { Total } \\
\text { (ng) }\end{array}$ \\
\hline-10 & 0 & 340.0 & 340.0 \\
0 & 6.2 & 299.4 & 305.6 \\
15 & 6.0 & 270.9 & 303.3 \\
30 & 39.1 & 278.8 & 317.9 \\
45 & 67.2 & 278.3 & 345.5 \\
60 & 55.4 & 286.3 & 341.7 \\
75 & 103.8 & 228.9 & 332.7 \\
90 & 60.9 & 304.2 & 365.1 \\
105 & 62.0 & 280.3 & 342.3 \\
120 & 103.6 & 250.0 & 353.6 \\
135 & 101.7 & 257.8 & 359.5 \\
150 & 129.6 & 205.3 & 334.8 \\
165 & 116.7 & 229.8 & 346.5 \\
180 & 130.5 & 233.2 & 363.7 \\
195 & 138.8 & 227.7 & 366.5 \\
210 & 99.9 & 245.9 & 345.8 \\
\hline
\end{tabular}


Table 4. Fentanyl Uptake of Two Different Supraseturated Primes [Prime Membrane Uptake (ng/ $\left.\left.\mathrm{cm}^{2}\right)\right]$

\begin{tabular}{rcc}
\hline $\begin{array}{c}\text { Time } \\
\text { (min) }\end{array}$ & $\begin{array}{c}255 \mathrm{ng} / \mathrm{mL} \\
\text { Prime }\end{array}$ & $\begin{array}{c}200 \mathrm{ng} / \mathrm{mL} \\
\text { Prime }\end{array}$ \\
\hline-10 & 0 & 0 \\
0 & 2.4 & 2.95 \\
15 & 22.8 & 25.5 \\
30 & 41.2 & 36.2 \\
45 & 52.1 & 47.9 \\
60 & 61.9 & 53.6 \\
75 & 67.7 & 61.5 \\
90 & 80.7 & 73.9 \\
105 & 89.2 & 78.6 \\
120 & 88.8 & 89.1 \\
135 & 98.4 & 98.0 \\
150 & 114.6 & 100.1 \\
165 & 116.7 & 98.9 \\
180 & 124.4 & 105.7 \\
195 & 123.7 & 107.8 \\
210 & 131.1 & 111.9 \\
225 & 114.1 & 116.6 \\
\hline
\end{tabular}

the 10 and $20 \mathrm{ng} / \mathrm{mL}$ primes throughout the course of the experiment. These uptake relationships can also be described numerically: for the $20 \mathrm{ng} / \mathrm{mL}$ solution, Uptake $\left(\mathrm{ng} / \mathrm{cm}^{2}\right)=1.3+$ $0.16 x$ to $0.00033 x^{2}$. For the $10 \mathrm{ng} / \mathrm{mL}$ solution, Uptake $\left(\mathrm{ng} / \mathrm{cm}^{2}\right)=0.63+0.076 x$ to $0.00017 x^{2}$.

In experiment 5, the isolated membrane square was studied in a fentanyl concentration similar to that of experiment 3 with the simple addition of motion to the priming solution. Rapid fentanyl uptake occurred over the first $30 \mathrm{~min}$ utes, and the membrane became saturated at $\sim 130 \mathrm{ng} / \mathrm{cm}^{2}$. The rate of uptake in this model resembled that observed in the intact membrane sample. The correlation between the circulated isolated and intact membrane was $r=0.913$.

\section{DISCUSSION}

For these experiments and those previously described by Koren et al, ${ }^{3,5,7}$ Scimed membrane oxygenators were used. Scimed brand membranes are silicone-based membranes with a nonporous sheetlike structure. Other currently available membranes are made with silicone, polypropylene, or other combinations of synthetic microporous materials in sheet or tubular structures. The behavior of other membrane brands should not be assumed to be similar to that of the Scimed membranes. The Scimed oxygenator has two continuous sheets of membrane wound about the central core (Fig 1). The oxygen interface surfaces are partitioned by a meshwork frame. The priming solution separates the other contiguous surfaces. Although the membrane brand was the same, the method of fentanyl detection was quite different in this study. All prior studies monitored only the disappearance of fentanyl from the prime solution and postulated that the membrane oxygenator was the site of binding. Use of tritiated fentanyl allowed analysis of both the prime solution and the oxygenator itself. The only site in the oxygenator other than the membrane material that contributes to the absorption of the fentanyl is the silicone wrapper sheet that surrounds the membrane to provide a watertight seal (Fig 1). In an intact membrane oxygenator, $1 \%$ to $2 \%$ of the fentanyl uptake could be attributed to binding by the silicone wrapper. This was true for

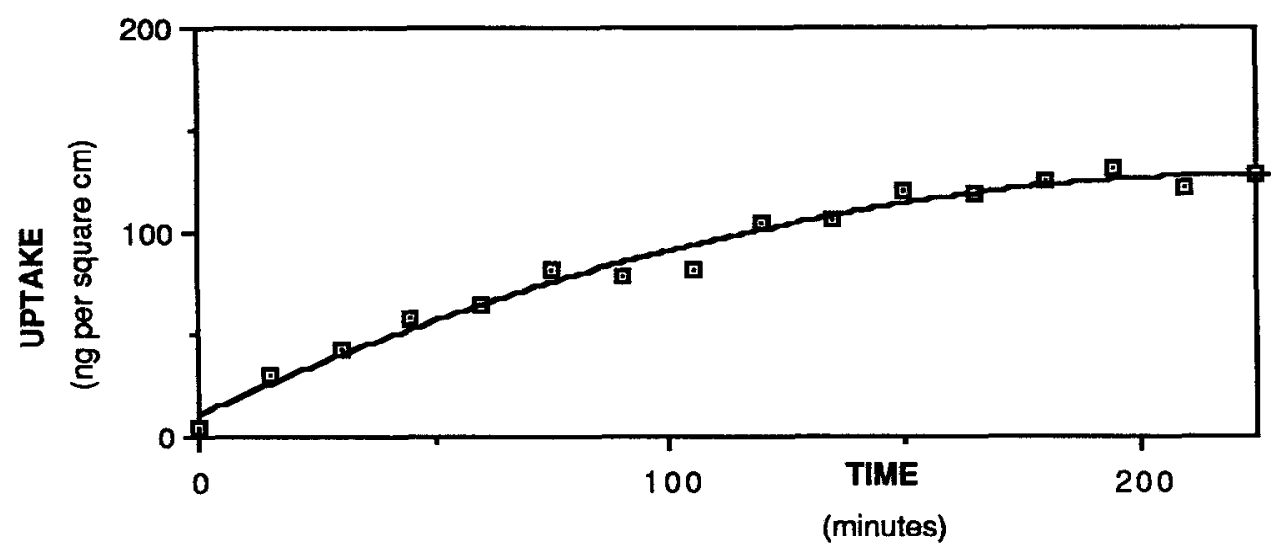

Fig 3. Uptake of isolated membrane squares exposed to uncirculated suprasaturated prime. 


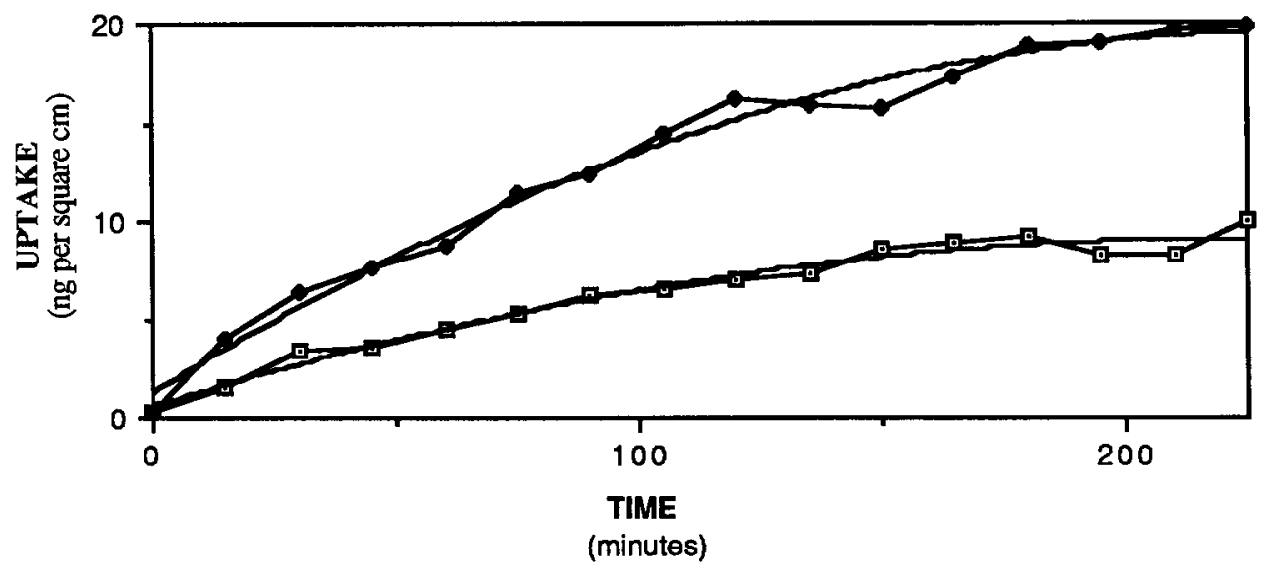

Fig 4. Uptake of isolated membrane exposed to uncirculated 10 - and $20-\mathrm{ng} / \mathrm{mL}$ solutions over time. (-๑-) $10 \mathrm{ng} / \mathrm{mL}, \mathrm{y}$ $=0.6327+0.0764 x-1.702 \theta-4 x^{2}, r=0.99 ;(-1) 20 \mathrm{ng} / \mathrm{mL}, \mathrm{y}=1.3361+0.1561 \mathrm{x}-3.290 \mathrm{e}-4 \mathrm{x}^{2}, r=0.99$.

both intact membrane studies (experiments 1 and 2), despite a threefold difference in fentanyl priming concentration.

In experiment 1 , study conditions used by Koren et $\mathrm{al}^{3,5,7}$ were reproduced to confirm the efficacy of the present methods. The use of tritiated fentanyl to analyze the fentanyl content was validated as an alternative to gas chromatographic techniques which other investigators used. ${ }^{3.5 .7 .8 .9}$ Koren et al used a fentanyl concentration of $120 \mathrm{ng} / \mathrm{mL}$ and found a $74 \% \pm 8.7 \%$ drop in the circulating fentanyl concentration in vitro using an assembled CPB circuit on first pass through the membrane. ${ }^{5}$ This was similar to the present study's $68 \%$ first-pass reduction by the assembled circuit membrane using a similar starting concentration $(125 \mathrm{ng} / \mathrm{mL})$.

The initial object of experiment 3 was to evaluate the behavior of isolated membrane squares in comparison to the intact membrane oxygenator. Although the initial fentanyl concentration was similar to the intact circuit of experiment 1 , the subsequent rate of rise of fentanyl concentration on the membranes was not. Later phases of the experiment identified differences in methodology, which explain this discrepancy. When these experiments ( 1 and 3 ) were performed, the saturation point of the membrane was unknown. This was subsequently determined. Both priming solutions contained fentanyl concentrations considerably below that necessary for saturation. In experiment 1 , only $6.2 \mathrm{ng}$ of fentanyl was available per square centimeter of membrane as compared to $34.7 \mathrm{ng}$ of fentanyl per square centimeter of membrane in experiment 3. During the 120 minute study period, $\sim 90 \%$ of fentanyl available was bound to the membrane. In addition, the rate of rise of fentanyl activity on the membrane was shown to be a function of the amount of fentanyl available when a subsaturated prime is used. Finally, movement of the fentanyl priming solution increases the rate of binding, as determined by experiment 5 . The earlier isolated membrane study (experiment 3 ) did not use a circulating method.

A similar pair of experiments studied the isolated membrane samples and intact membrane in the CPB circuit under conditions in which saturation was achieved. The saturation point of the silicone membrane was determined to be $\sim 130 \mathrm{ng} / \mathrm{cm}^{2}$. This was found both in the intact membrane (experiment 2) in the CPB circuit and in the isolated membrane model (experiment 4) at different suprasaturated priming concentrations. Isolated membrane fentanyl binding in an uncirculated suprasaturated solution achieved equilibrium at 150 minutes. This point is reached more rapidly in the intact circulated circuit. Although both experimental systems approach an equilibrium of fentanyl binding at the same level, the kinetics of this association are not the same in the two models. When circulatory motion was applied to the isolated membrane squares (experiment 5), the resultant rate of uptake closely resembled the intact membrane circuit at full flow. The creation of a boundary layer deficient in substrate is 
potentially responsible for the decreased rate of uptake in the noncirculated isolated membrane studies. This also would serve to explain the irregularity in the slope of the absorption curve. An example would be the apparent fall in fentanyl uptake at 210 minutes in experiment 3 (Table 3 ). The boundary layer is a recognized concept in membrane oxygenator dynamics, and elimination or minimization of this effect is critical to maximize the oxygenator efficiency. ${ }^{10-12}$ The boundary layer is formed because not all of the prime is actually in contact with the membrane. The fluid in immediate proximity to the membrane surface interacts faster than that farther away. Turbulence allows mixing of this layer effect. It is the boundary layer phenomenon that creates one of the primary limitations to transfer of gases and chemicals across the membrane. The boundary layer is minimized by the Scimed oxygenator structure by implanting dacron fibers within the silicone sheet to provide surface contour. As the prime in the CPB moves across this surface, it creates turbulence which helps to minimize the boundary layer phenomenon. The turbulence created by a vortex mixer (experiment 5) is similar to the continuously flowing solution in the intact CPB circuit and minimizes the boundary layer formation suggested in earlier experimental phases.

The membrane appears to be faster and more effective in binding fentanyl when suprasaturated concentrations are used, and the ratio of fentanyl concentration to membrane surface area is high. Comparison of the uptake formulas for the two subsaturated solutions indicates that the slope for the $20 \mathrm{ng} / \mathrm{mL}$ solution is twice that of the $10 \mathrm{ng} / \mathrm{mL}$ solution. Membrane samples exposed to a fentanyl concentration of 10 and 20 $\mathrm{ng} / \mathrm{mL}$ absorbed all available fentanyl after 210 minutes. For all subsaturated solutions tested, both intact and isolated, $>80 \%$ of the available fentanyl was membrane bound by two hours. Experiment 3 confirmed that the uptake of fentanyl was much greater than had been initially anticipated from work by Koren et al. ${ }^{3,5,7}$ Therefore, a concentration 2.5 times that available in experiment 3 was used for experiments 2 and 4 in order to attain saturation.

Clinical studies like that of Koren et al ${ }^{3,5,7}$ have shown that even when the prebypass fentanyl levels were $>20 \mathrm{ng} / \mathrm{mL}$, the initiation of hypothermic bypass resulted in a rapid fall far below $20 \mathrm{ng} / \mathrm{mL}$. The levels continued to be low throughout the bypass period. ${ }^{3}$ Skacel et al used a circuit with a bubble oxygenator. ${ }^{8}$ Many bubble oxygenators use a synthetic mesh for debubbling of oxygenated blood, which would also be predicted to remove circulating fentanyl. They also used silicone-containing pump head tubing. Skacel et $\mathrm{al}^{8}$ postulated the binding mechanism to be $\mathrm{pH}$-dependent hydrophobic uptake. The $\mathrm{pH}$ effect that they proposed should have minimal effect in the clinically relevant $\mathrm{pH}$ range around 7.4 .

Under the present experimental conditions, the capacity of the Scimed membrane for fentanyl is enormous (Table 5). To calculate the amount of fentanyl required to saturate the oxygenator, the membrane surface area in $\mathrm{cm}^{2} \times$ $130 \mathrm{ng}$ is multiplied. The standard adult Scimed membrane oxygenator (model $3500-2 \mathrm{~A}$ ) with a surface area of $3.5 \mathrm{~m}^{2}$ would require $>4.5 \mathrm{mg}$ of fentanyl. In addition, the desired plasma concentration must be achieved in the priming solution. When patients are believed to need additional anesthesia, the technique of adding small amounts of fentanyl to the unsaturated CPB apparatus would have less effect than expected because the membrane is capable of absorbing most of the dose on the first pass.

Although this study identified two significant factors which modify the in-vitro fentanyl interaction, fentanyl concentration and fluid motion, more variables need to be examined before these results are applied to the clinical setting. Potential modifiers of this interaction include the protein content of the CPB prime solution, the use of blood cells and/or plasma, temperature, $\mathrm{pH}$, and concurrently administered drug interactions. One important issue is the nature of the interaction with regard to revers-

Table 5. Predicted Fentanyl Absorption of Various Scimed Membranes by Size

\begin{tabular}{lclc}
\hline Model No. & $\begin{array}{c}\text { Surface } \\
\text { Area }\left(\mathbf{m}^{2}\right)\end{array}$ & $\begin{array}{c}\text { Patient } \\
\text { Weight (kg) }\end{array}$ & $\begin{array}{c}\text { Predicted Fentanyl } \\
\text { Absorptive Capacity (mg) }\end{array}$ \\
\hline 0400-2A & 0.4 & Up to 4 & 0.52 \\
0800-2A & 0.8 & Up to 11 & 1.04 \\
$1500-2 A$ & 1.5 & $12-19$ & 1.95 \\
$2500-2 A$ & 2.5 & $20-70$ & 3.25 \\
$3500-2 A$ & 3.5 & $71-95$ & 4.55 \\
$4500-2 A$ & 4.5 & $>96$ & 5.85 \\
\hline
\end{tabular}


ibility. Can fentanyl bound to the membrane in a clear priming solution be removed by subsequent mixing with the patient's blood? Through future consideration of these unknown variables, it may be possible to refine the study technique further and increase clinical applications. It is recognized that many changes occur when CPB is initiated. Because of the complexity of the interaction, a model that can examine all of the patient-membrane interaction has not been possible to devclop. It is hoped that by understanding the component parts, it may be possible to approach this model.

Although fentanyl binding on Scimed membranes is noted in the current and previous studies, utilization of other membrane brands of different structure and/or composition may not produce the same results. The present techniques can be applied to examination of other membrane brands with similar sheetlike structure. Modification of the method will be necessary to study membranes with different structural form.

In conclusion, it has been demonstrated that the Scimed silicone-based membrane is capable of rapidly absorbing a considerable quantity of fentanyl. The membrane continues to absorb fentanyl until it is saturated. In this study, two factors that influence this interaction were identifed. The rate of absorption is dependent on the fentanyl concentration available in the solution and on circulation of the solution. When suprasaturated priming solutions are used, the capacity for fentanyl uptake is not altered by these factors. Saturation appears to be reached at $\sim 130 \mathrm{ng} / \mathrm{cm}^{2}$ for the intact and isolated Scimed membrane. An isolated membrane model was developed that accurately reflects the capacity of the intact membrane for fentanyl binding. When the isolated priming solution is stirred, a condition that mimics circulation of the prime through the CPB circuit, the resultant kinetics of uptake also correlate. The cost incurred when the intact bypass circuit is primed with radiolabeled drug is high. The isolated membrane model is a means of studying membrane interaction characteristics that efficiently conserve experimental supplies and funds. It is planned to use this model to explore the characteristics of other membrane brands, different drug interactions, and variations in the priming solution. The simplification of fentanyl membrane interactions and study of individual variables will, hopefully, lead to a better understanding of the well-described clinical phenomenon. Development of a laboratory model applicable to a wide variety of clinical situations is the ultimate goal.

\section{ACKNOWLEDGMNT}

We thank Kimberly Ann Henry for her support in preparation of the manuscript.

\section{REFERENCES}

1. Singleton MG, Rosen J, Fisher D: Plasma concentrations of fentanyl in infants, children, and adults. Can J Anaesth 34:2, 152-155, 1987

2. Koehntop D, Rodman J, Brundage D, et al: Pharmacokinetics of fentanyl in neonates. Anesth Analg 65:227232, 1986

3. Koren G, Goresky G, Crean P, et al: Pediatric fentanyl dosing based on pharmacokinetics during cardiac surgery. Anesth Analg 63:577-582, 1984

4. Bentley JB, Conahan TJ, III, Cork RC: Fentanyl sequestration in lungs during cardiopulmonary bypass. Clin Pharmacol Ther 34:5, 1983

5. Koren G, Crean P, Klein J, et al: Sequestration of fentanyl by the cardiopulmonary bypass. Eur J Clin Pharmacol 27:51-56, 1984

6. Koska AJ, III, Romagnoli A, Kramer WG: Effect of cardiopulmonary bypass on fentanyl distribution and elimination. Clin Pharmacol Ther 29:1, 1981
7. Koren G, Crean P, Goresky G, et al: Irreversible binding of fentanyl to the cardiopulmonary bypass. Anesth Analg 63:175-184, 1984

8. Skacel M, Knott C, Reynolds F: Extracorporeal circuit sequestration of fentanyl. Br J Anaesth 68:947-949, 1986

9. Gillespie TJ, Gandolfi AJ, Maorino RM, Vaughan RW: Gas chromatographic determination of fentanyl and its analogues in human plasma: J Anal Toxicol 5:133-137, 1981

10. Nelson M: The heart: Extracorporeal circulation, in Sabiston DC (ed): Textbook of Surgery, Saunders, Philadelphia, 1981, pp 2450-2460

11. Varco RL (ed): Conference on mechanical surface and layer effects on moving blood. Fed Proc 30:14851488,1971

12. Barlett RH, Kittredge D, Nayes BS, et al: Development of a membrane oxygenator: Overcoming blood diffusion limitation. J Thoracic Cardiovasc Surg 58:795-819, 1969 